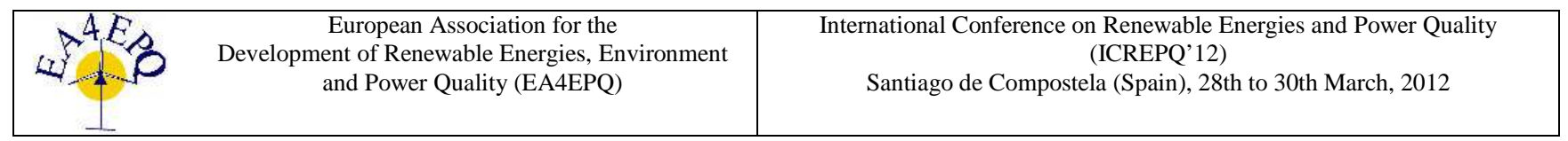

\title{
Renewable Energy in Residential Buildings Analysis of different micro-generation systems
}

\author{
M. Rodrigues ${ }^{1}$, M. Valdez ${ }^{1}$ and D. Coelho ${ }^{1,2}$ \\ ${ }^{1}$ ISEC - College of Engineering of Coimbra \\ Rua Pedro Nunes - Quinta da Nora, 3030-199 Coimbra, Portugal \\ Phone/Fax number:+00351239790200,e-mail: miguel.jr.rodr@hotmail.com,valdez@isec.pt, dcoelho@isec.pt \\ 2 INESC Coimbra, Portugal
}

\begin{abstract}
Portugal has to meet a target of $31 \%$ regarding the share of renewable sources on gross final energy consumption, including $10 \%$ in transportation, to meet the targets imposed on greenhouse gas emissions, energy efficiency and use of renewable energy by the European Commission Climate Change and Energy package for 2020 The implementation of the new National Strategy for Energy - ENE 2020, defining an agenda for competitiveness, growth and energy and financial independence, by investing on renewable energies and promoting the energy efficiency, assuring the security of supply and the economical and environmental sustainability of the national energy model; contributing to the reduction of $\mathrm{CO} 2$ emissions, will enable Portugal to meet commitments assumed within the context of European policies. In the National Action Plan for Energy Efficiency Portuguese Government stated the goal of achieving $165 \mathrm{MW}$ of micro-generation installed capacity by the year of 2015. In this context, and according to the new Portuguese law concerning micro-generation to promote renewable energy sources in households, we present in this paper a technicaleconomic analysis of different micro-generation systems that can be installed in a single-family house. This analysis will take into account the local availability of renewable resources and market technologies.
\end{abstract}

\section{Key words}

Micro-generation, Renewable energies, Solar photovoltaic, Wind energy.

\section{Introduction}

After the approval of the so-called Climate Change and Energy package, targets were set for 2020. Green House Gases (GHG) emissions will have to be reduced by $20 \%$ with respect to 1990 levels, renewables (RES) will have to contribute $20 \%$ to gross energy consumption in the EU, energy efficiency should improve by 20 percentage points and the share of biofuels in transport will have to be $10 \%$ of energy consumption. The $20 \%$ RES in final energy consumption is included in a new RES Directive [1].
In this context, Portugal has to meet a target of $31 \%$ regarding the share of renewable sources on final energy consumption, including $10 \%$ in transportation.

Portugal has privileged conditions for sustainable development in the field of renewable energy. Nowadays, most of the energy from renewable sources is generated from large wind and photovoltaic farms. However, consumers at low voltage level represent a fundamental part in the expansion of the use of RES by installing microgeneration systems with subsequent sale of the produced energy to the electric grid.

The installation of microgeneration systems is one of the strategies for improving energy performance of buildings (residential and services buildings).

In the National Action Plan for Energy Efficiency Portugal Efficiency 2015 (PNAEE) [2], an aggregating action plan for a series of energy efficiency programmes and measures, encompasses four specific areas, Portuguese Government include in the specific area Residential and Services, the "Renewable at the Time and Solar Programme" (see Figure 1), a programme oriented towards increased penetration of ownproduction energies in the residential and service sectors. This programme aims to promote replacement of fossil fuel consumption with renewable energies, through easier access to electricity micro-generation technologies and solar heating technologies. Portuguese Government stated the goal of achieving $165 \mathrm{MW}$ (75 thousand electricity-producing homes) of micro-generation installed capacity by the year of 2015 , starting with 10 MW for 2008 and increasing by $20 \%$ every year and one in every 15 buildings with Solar Hot Water. It is expected to directly contribute for a major goal of $31 \%$ of renewable generation by 2020 as part of the EC 2020 target [3]. 

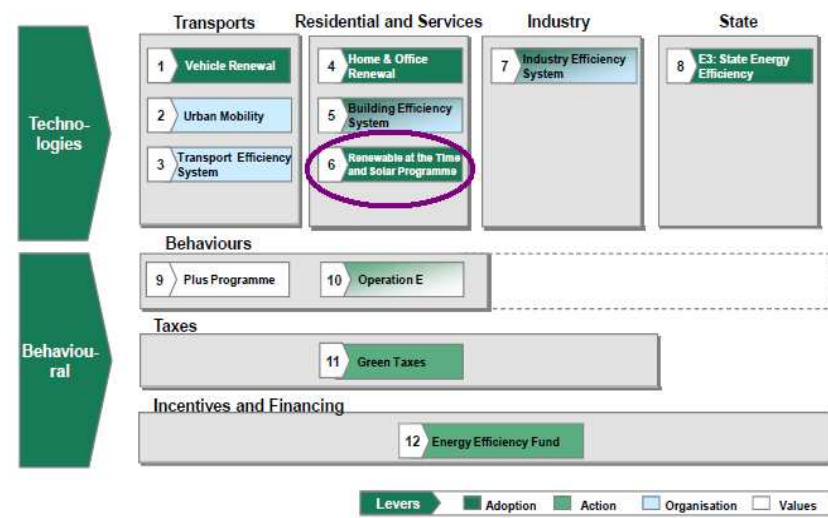

Source: Based on [2]

Fig. 1. PNAEE - specific areas and programmes

The new National Strategy for Energy - ENE 2020 (see Cabinet Resolution 29/2010of 15th of April [4]), defining an agenda for competitiveness, growth and energy and financial independence, by investing on renewable energies and promoting the energy efficiency, assuring the security of supply and the economical and environmental sustainability of the national energy model; contributing to the reduction of $\mathrm{CO}_{2}$ emissions.

The National Strategy for Energy has been structured around 5 main axes, one of which is entirely dedicated to RES, establishing targets and strategies to develop and promote the various technologies that are part of the mix of renewable energies by 2020 . This is aimed at enhancing the potential of endogenous resources and the capacity to create value, with a view to ensuring a greater diversification for the contributions of the RES. The implementation of this new strategy assumes the Institutional brand: Re.New.Able. - New Energy to inspire Portugal and adapts and updates the previous strategy, approved by Cabinet Resolution $n^{\circ} 169 / 2005$, of 24th October. This will enable Portugal to meet commitments assumed within the context of European policies.

The National Renewable Energy Action Plan (NREAP) [5], prepared and written on the basis of the Commission Decision of 30 June 2009, which provides for a template for national renewable energy action plans in the Directive 2009/28/EC, includes measures for achieving renewable energy targets and an overview of all policies and measures to promote the use of energy from renewable sources.

This work has been developed in the framework of a Master dissertation currently under development, which the main objective is the selection of the most appropriate micro-generation system to be installed in a dwelling. According to the new Portuguese law concerning microgeneration to promote renewable energy sources in households, and taking into account the local availability of renewable resources and market technologies, we present a technical-economic analysis of four different micro-generation systems that can be installed in a singlefamily house: three photovoltaic systems and one wind turbine system.

\section{Microgeneration - Legal Framework}

Microproduction was initially regulated by Decree-Law $68 / 2002$ [6], according to which at least $50 \%$ of the electricity produced by generators and solar panels must be consumed by the producer or by connected third parties. Furthermore, the power that was transmitted to the national grid at each connection point could not exceed $150 \mathrm{~kW}$. After five years of coming into effect, the number of microproducer units did not achieve an expressive number. The new Decree-Law [7] which simplified the rules for private production of electricity from solar, wind, water and other sources of energy was then approved, defining namely: what is required to become an electricity producer, the rights and duties of the producers, the role of Directorate General for Energy and Geology (DGEG) - the organization that manages this sector, which companies may install microproduction units and the price paid for the electricity produced situations in which a higher price is paid (initial tariff of $650 € / \mathrm{MWh}$ for photovoltaic panels, $455 € / \mathrm{MWh}$ for wind turbines).

From then on licensing started being conducted through the internet, via the System of Registration of Microproducers (SRM), an electronic platform where producers may register their installations. This new framework got a very enthusiastic response, with the fulfilment of the capacity registered. Afterwards, some difficulties have arisen, related with the lack of adequate equipment and shortage of licensed installers [8].

In order to be covered by this legislation, the microproduction unit had to meet some requirements, including: a contract for the purchase of LV electricity; it was compulsory to install a minimum of $2 \mathrm{~m}^{2}$ of solar thermal panels in cases where solar or wind systems were being installed, in order to access the subsidised tariff regime. Additionally, as stipulated in Decree-Law $363 / 2007$, a series of technical rules has been approved to support the implementation of microproduction, guaranteeing the suitable functioning of the system.

During 2008 about 3600 microgeneration plants started their certification process and 808 were certified or connected to the public LV grid. Regarding the tariff incentives and the solar exposition in Portugal, as well as the modularity, scalability and low maintenance requirements of the Photovoltaic (PV) systems, this technology met, by far, the preferences of promoters. Up to the end of $2008,95 \%$ of the units certified or connected to the grid were PV systems, $4 \%$ wind turbines and $1 \%$ hybrid systems [8].

The National Renewable Energy Action Plan [5], among other measures foresees the review of the existing microgeneration legislation (see Figure 2).

The new microgeneration legislation, Decree-Law $118 \mathrm{~A} / 2010$ [9], modifies some aspects of the Microgeneration Law. The new regulation increased the annual ceiling for installation to $25 \mathrm{MW}$ per year and streamlined the access to the microproduction regime for 
public, social, education, defence and local institutions. Moreover, the beneficed regime was adjusted to the cost of equipment used in the microproduction and could only be accessed under certain conditions, namely the compliance with energy efficiency measures and the use of solar thermal collectors or biomass boilers.

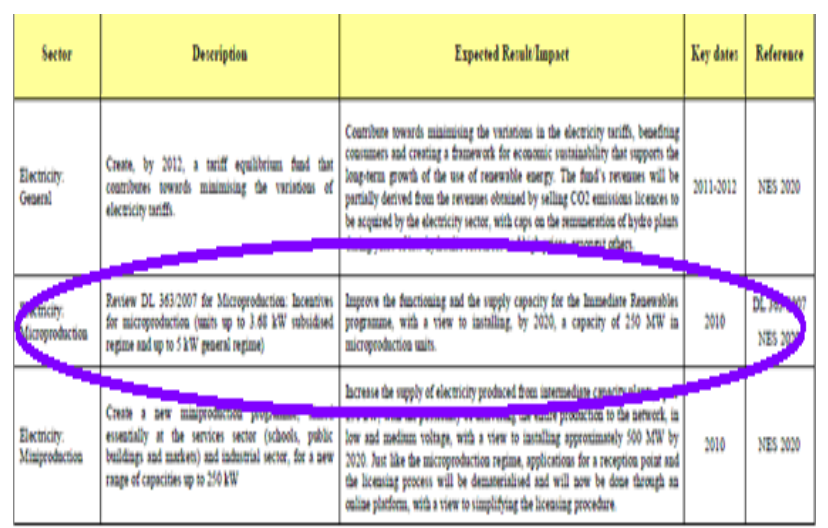

Fig. 2. Measures for achieving the targets (NREAP)

Figure 3 depicts the evolution of the price for energy selling to electric grid over the lifetime of the investment, by microgeneration technology, according new legislation: $400 € / \mathrm{MWh}$ for the first period and 240€/MWh, with an annual reduction of $20 € / \mathrm{MWh}$. The reference tariff applied $100 \%$ for solar and $80 \%$ for wind.

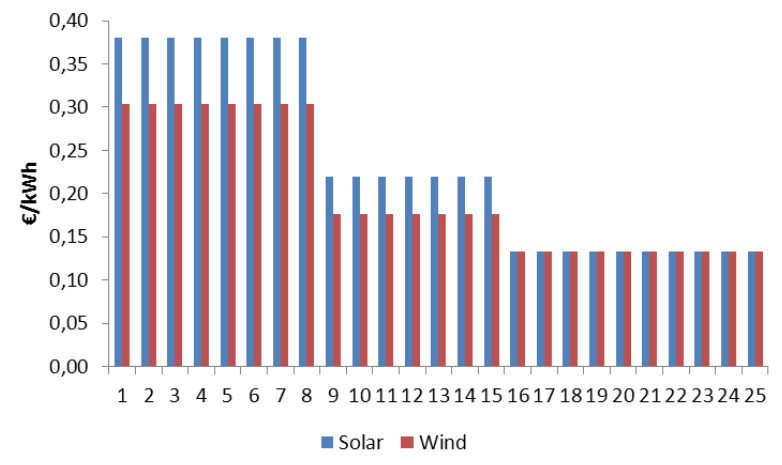

Fig. 3. Evolution of the price for energy selling.

Fidaldo and Fontes [10] argue that current legislation should be reviewed and the existing regulatory constraints should be relaxed in order to allow for higher levels of MG penetration. According to the results of their study, microgeneration penetration levels of up to at least $50 \%$ have a positive technical impact on the power networks. The current regulatory directive limits the installation of microgeneration to $25 \%$ of the transformer capacity installed in the secondary substation.

\section{Analysis of different micro-generation systems}

\section{A. Dwelling characterization}

The dwelling under study is a 3-story single-family house, located in the centre of Portugal, near Sicó's mountain. Housing has already installed 2 square meters of solar thermal collectors, which are embedded in the dwelling's heating system. This is a mandatory requirement for the access to microgeneration activity.

Dwelling is supplied at Low Voltage (10,35kVA) from the public grid (another mandatory requirement to the microgeneration activity). Total electricity consumption during 2010 ranges from $366.8 \mathrm{kWh}$ in February to $471.20 \mathrm{kWh}$ in December, in a total annual consumption of $4905 \mathrm{kWh}$ (see Figure 4), which correspond to an annual electricity bill of $838.20 €$.

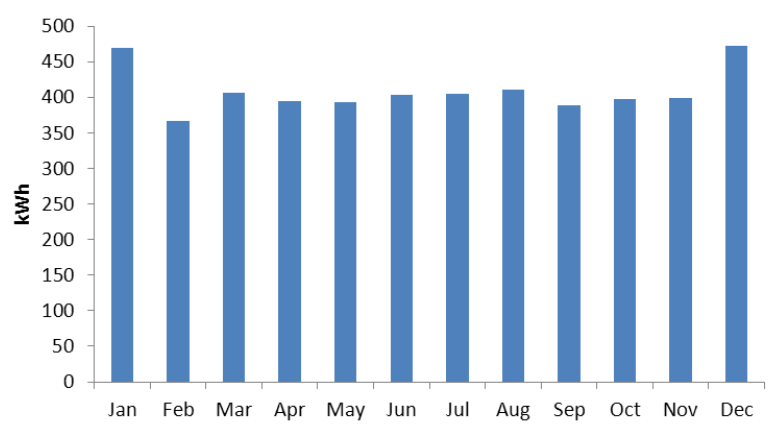

Fig. 4. Electricity annual consumption in a monthly basis.

\section{B. Local renewable resources potentials}

Several factors affect the development and deployment of electricity from renewable energy systems, namely techno-economic factors, legal and administrative barriers, political factors and social acceptability. Pablo del Río provides an overview of all these factors [11].

For an economically feasible performance of solar energy systems, one of the main influencing factors is the availability of solar energy on ground surface that can be converted into heat or electricity. Solar irradiation means the amount of energy that reaches a unit area over a stated time interval, expressed as $\mathrm{Wh} / \mathrm{m}^{2}$. Solar radiation can be divided into direct and diffuse radiation. Together these components are denoted as global irradiation (see Figure 5).

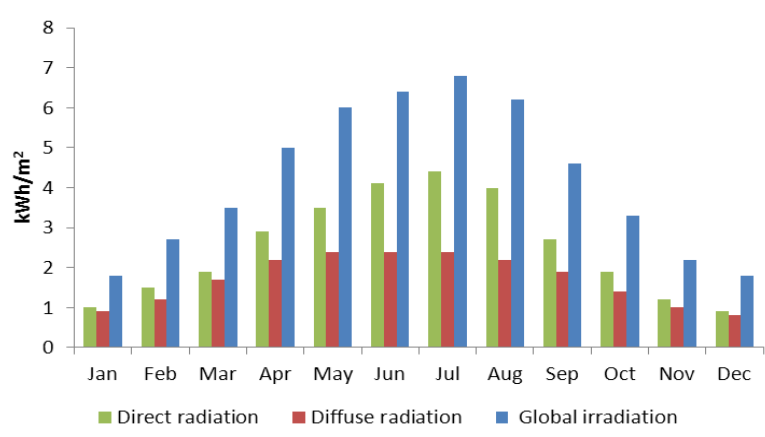

Fig. 5. Monthly average of horizontal solar irradiation.

The electricity output of a wind turbine system depends on several factors, namely geographic location, meteorological conditions and the height of the wind turbine above ground.

From the data base EOLOS, a data base of the wind potential in Portugal [12], has been possible to obtain the 
wind potential for the local under study. Monthly average wind speed in Sicó's mountain is presented in Figure 6.

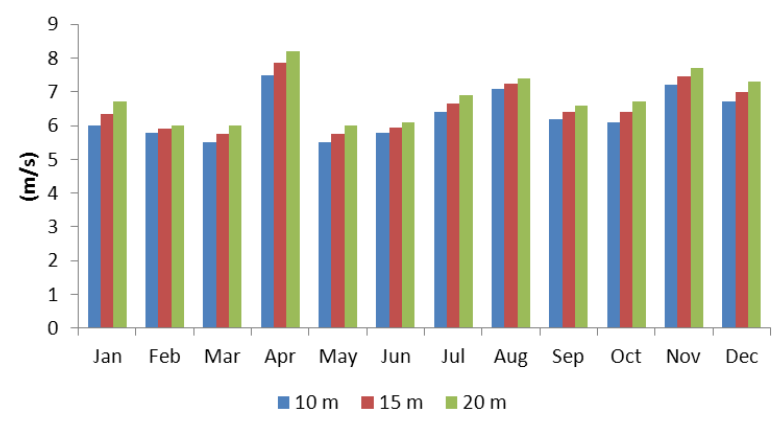

Fig.6. Monthly average wind speed in Sicó’s mountain.

\section{Analysis of microgeneration systems}

The energy performance and the economic analysis of the microgeneration systems have been achieved with the software SolTerm [13]. The main results are presented in the next sections: Cumulative cash flow (the sum of all cash inflows and outflows for all preceding years and the current year); Net Present Value (NPV - an indicator of the value-added of the investment or project); Internal Rate of Return (IRR - used to evaluate the desirability of investments or projects) and payback period (a financial metric that indicates how long does an investment takes to pay for itself).

\section{1) Fixed PV system}

The system will be composed of several elements namely: the field of collectors with 18 photovoltaic solar panels with a total peak power of $4050 \mathrm{~W}$ and a utility-gridconnected inverter (to convert the PV modules' DC output to AC compatible with the utility grid). The total investment cost of the system is $16046 €$.

Taking into account the evolution of the price for energy selling to electric grid (see Figure 3), annual energy production and annual maintenance costs, we obtained the results of the economic analysis of the fixed PV system. The cumulative cash flow for the fixed PV system is presented in Figure 7.

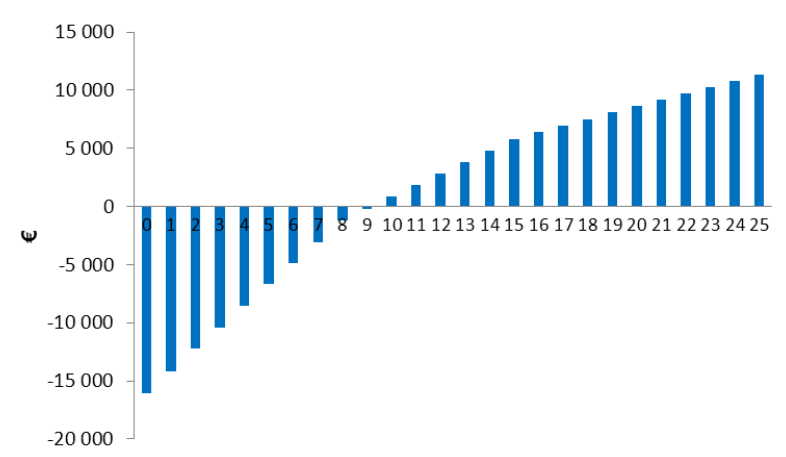

Fig. 7. Cumulative cash flow $(€)$ for the fixed PV system.

From this analysis it appears that the simple payback system will be 10.2 years, the Internal Rate of Return of $6.64 \%$ and the Net Present Value of $723.19 €$.

\section{2) Mono-axis PV system}

The mono-axis PV system will be very similar with the fixed PV system. The system consists in a total of 18 photovoltaic solar panels for a total of $4.05 \mathrm{kWp}$ of installed power. As expected, this system is more expansive, with a total investment cost of $19447 €$.

Based on the assumptions used previously, we obtained the evolution of the cumulative cash flow for the Monoaxis PV system that is presented in Figure 8.

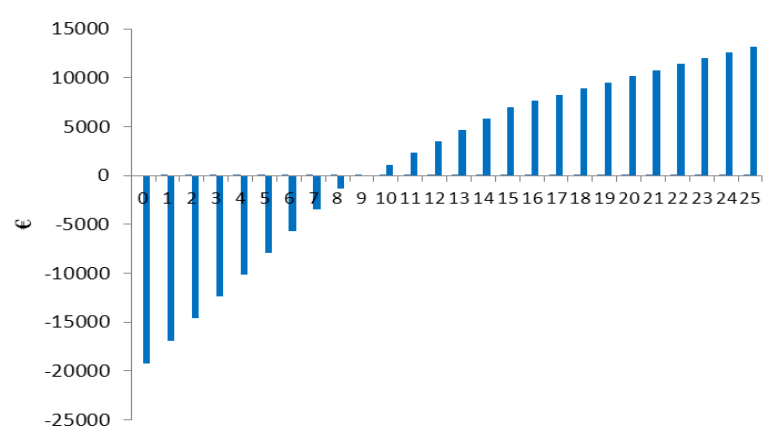

Fig.8. Cumulative cash flow (€) for the Mono-axis PV system.

For this system the simple payback period will be 10.16 years, the Internal Rate of Return of $6.6 \%$ and the Net Present Value of $793 €$.

Despite the cost of this mono-axis PV system is higher than the cost of the fixed PV system, the payback period is lower. This is due to the fact that a panel mounted on a solar tracker maximises its output.

\section{3) Bi-axis PV system}

A two-axis tracking surface can increase the productivity of the PV modules. The reason is due to the possibility of following the sun's position throughout the day, setting the azimuthal angle, and throughout the year, adjusting the zenith angle, maximizing photoelectric conversion.

The composition of this system is similar with the two previous systems, with a total investment cost of 19989 $€$.

From the evolution of the cumulative cash flow for the bi-axis PV system, presented in Figure 9, it appears that the simple payback system will be 9.28 years, the Internal Rate of Return of $6.79 \%$ and the Net Present Value of $1078.01 €$.

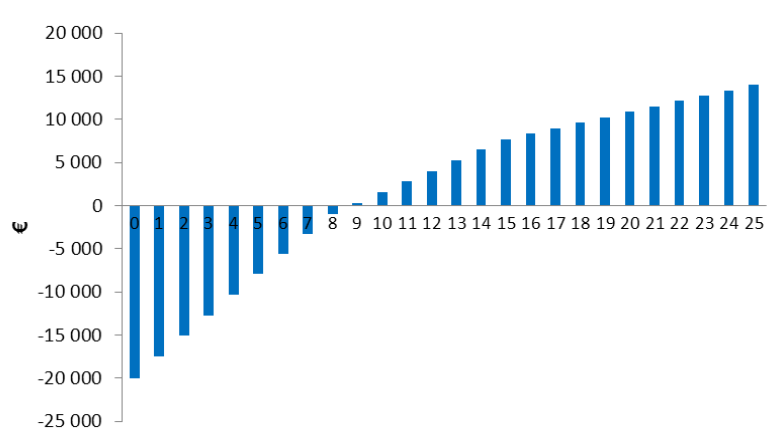

Fig.9. Cumulative cash flow ( $€$ ) for the Bi-axis PV system. 


\section{4) Wind turbine system}

The wind turbine system is composed by a horizontal axis micro turbine of $3.5 \mathrm{~kW}$ and the total investment cost is $14472 €$

The evolution of the cumulative cash flow for the wind turbine system is presented in Figure 10. For this system the simple payback system is higher than 11 years, the Internal Rate of Return is $5.93 \%$ and the Net Present Value is a negative value, $-75.28 €$. This negative value for NPV means that the investment is not economically viable, despite its payback period be lower than the lifetime of the wind system.

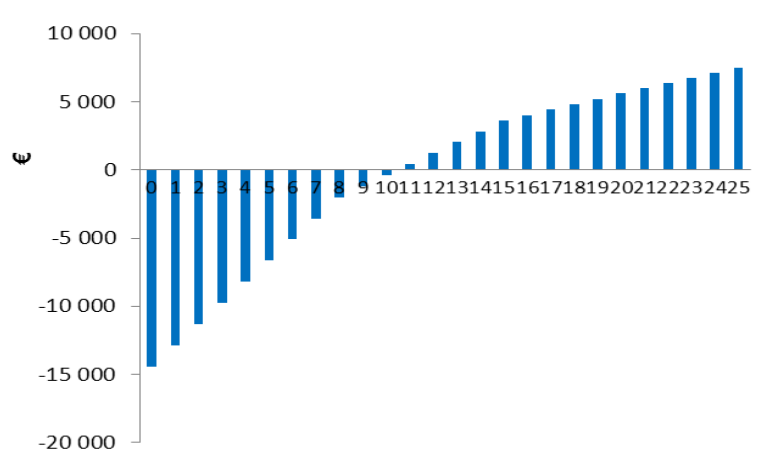

Fig.10. Cumulative cash flow (€) for the Wind turbine system.

The evaluation of the four microgeneration systems considered in this work is resumed in Table I. The energy production and $\mathrm{CO}_{2}$ reduction values are average annual values.

Table I - Microgeneration systems evaluation.

\begin{tabular}{|c|c|c|c|l|c|}
\hline System & $\begin{array}{c}\text { Investment } \\
\text { cost }(€)\end{array}$ & $\begin{array}{c}\text { Energy } \\
\text { production } \\
\text { (kWh/year) }\end{array}$ & $\begin{array}{c}\mathrm{CO}_{2} \\
\text { reduction } \\
\text { (kg/year) }\end{array}$ & Payback & NPV \\
\hline Fixed PV & 16046 & 4624.12 & 2173.34 & 10.2 & 723.19 \\
\hline Mono-axis PV & 19447 & 5780.12 & 2716.11 & 10.16 & 793 \\
\hline Bi-axis PV & 19989 & 6242.65 & 2934.00 & 9.28 & 1078.01 \\
\hline Wind & 14472 & 5263.40 & 2473.80 & 11.2 & -75.28 \\
\hline
\end{tabular}

\section{Conclusions}

As part of the EC 2020 target, often known as the 20-2020 targets, the second target is that $20 \%$ of the total energy use within the EU should by 2020 come from renewable energy sources. Within the second target, there are different binding targets for the percentage of renewable energy sources for different countries in the union, where Portugal should have the highest share of $31 \%$ renewable energy sources by 2020 .

Portuguese Government stated the goal of achieving 165 MW (75 thousand electricity-producing homes) of microgeneration installed capacity by the year of 2015, starting with 10 MW for 2008 and increasing by $20 \%$ every year and one in every 15 buildings with Solar Hot Water.
It is foreseeable that the interest of electrical energy consumers in microgeneration technologies will increase, resulting on the integration of these units on a larger scale. Furthermore, technological developments allow the development of smartgrid concepts that will bring new capabilities to electrical grids.

In this work we present a technical-economic analysis of different microgeneration systems to help the decision for the selection of a system that can be installed in a singlefamily. According to the new Portuguese law concerning microgeneration to promote renewable energy sources in households, and taking into account the local availability of renewable resources and market technologies we present a technical-economic analysis of four different microgeneration systems: three photovoltaic systems and one wind turbine system.

It was found that the photovoltaic technology, with the financial support that currently exists in Portugal for micro-generation systems interfaced with the available electric grid, is a sustainable option, economically viable, financially rewarding and environmentally friendly.

\section{References}

[1] European Parliament and of the Council, Directive 2009/29/EC, Renewable Energy Sources, 23 April 2009.

[2] Council of Ministers Resolution 80/2008, Available at: http://www.min-economia.pt/document/PNAEE.pdf

[3] Europe's Energy Portal, Renewable energy in final energy consumption (2020 target), Brussels, 2008 [Online]: http://www.energy.eu/renewables/eucharts/RE-in-final.html.

[4] RCM 29/2010 (15.04.2010). Diário da República, 1. série - N. ${ }^{\circ} 73 / 1289$.

[5] NREAP, National Renewable Energy Action Plan, 2010. Available at:

http://ec.europa.eu/energy/renewables/transparency _platform/doc/national_renewable_energy_action_p lan_portugal en.pdf.

[6] Decree-Law 68/2002 (25.03.2002). Diário da República, 1. ${ }^{\mathrm{a}}$ série $\mathrm{A}-\mathrm{N} .{ }^{\mathrm{o}} 71 / 2837$.

[7] Decree-Law 363/2007 (2.11.2007). Diário da República, 1. ${ }^{a}$ série - N. ${ }^{\circ} 211 / 7978$.

[8] N. Melo, R. Prata, R. Gonçalves and F. Mira, "Micro generation In Portugal - EDP Experience and Future Perspectives, in Proc. 20th International Conference on Electricity Distribution, June 2009.

[9] Decree-Law 118-A/2010 (25.10.2010). Diário da República, 1. ${ }^{\text {a }}$ série - N. ${ }^{\circ} 207 / 4834$.

[10] J.N. Fidalgo, Dalila B.M.M. Fontes, "Fostering microgeneration in power systems: The effect of legislative limitations", Electric Power Systems Research, 2012, Vol. 84, pp. 181- 186.

[11] P. Río "Analysing future trends of renewable electricity in the EU, in a low-carbon context", Renewable and Sustainable Energy Reviews, 2011, Vol. 15, pp. 2520 2533.

[12] Instituto Nacional de Engenharia, Tecnologia e Desenvolvimento (INETI), Base de Dados do Potencial Eólico em Portugal - EOLOS, http://www.ineti.pt/viewDoc.aspx? src=C7B3D76B5EFC E7DA832880EEAD374110.

[13] SolTerm Software - Performance Analysis of Thermal and Photovoltaic Systems (in portuguese), INETI, Lisboa, 2008. 